\title{
A comparison of diltiazem and atenolol in angina
}

\author{
David Wheatley
}

The General Practitioner Research Group, 11 A Manor Court, Hinchley Wood, Surrey, KT10 0SP, UK.

\begin{abstract}
Summary: Diltiazem was compared to atenolol in a double-blind trial involving 78 patients suffering from coronary heart disease. Following a 2 week control period, patients were randomly allocated to 6 weeks treatment with one or the other drug.

The patients themselves made daily records of anginal attacks, trinitrate requirements, well-being and exercise tolerance. With both drugs there were highly significant reductions in the anginal attack rate and trinitrate requirements, and significant improvement on the other measures. However, there were no significant between drug differences.

The incidence of side effects with diltiazem was very low and no patient had to omit treatment for this reason, although three patients did so on atenolol.
\end{abstract}

\section{Introduction}

Drugs that block calcium flow at a cellular level provide a useful alternative to the beta-adrenergic blocking drugs in the treatment of coronary heart disease (CHD) and various other cardiovascular disorders (Zelis \& Flaim, 1982). Beneficial effects result from the ability of these drugs to reduce afterload, myocardial contractility and heart rate, and to increase coronary blood flow by direct dilatation of the large coronary arteries (Naylor, 1980). However, individual compounds of this group of drugs, which differ chemically from one another, have different relative potencies on these various cardiovascular functions (Stone et al., 1980; Ellrodt et al., 1980; McAuley \& Schroeder, 1982). Diltiazem (Tildiem), a 1,5 -benzothiazepine derivative, is the latest drug of this type to be introduced in the UK and is particularly potent in its coronary vasodilator activity (McAuley \& Schroeder 1982; Tartaglione et al., 1982).

Apart from the possibility of greater clinical effectiveness, the calcium antagonist drugs have the advantages over the beta-adrenergic blocking drugs in that they do not cause bronchospasm or cardiac failure in susceptible patients or vasospasm in Raynaud's disease (Awan et al., 1982). It therefore seemed appropriate to undertake a clinical trial of diltiazem in comparison to one of the most widely used betablocking drugs, namely atenolol (Tenormin), in patients suffering from CHD.

Correspondence: D. Wheatley, M.D., F.R.C.Psych. Accepted: 21 March 1985

\section{Methods and patients}

There was an initial 2-week control period, during which placebo was given, and patients continued with any non-anti-anginal medications that they were already taking. However, if a patient was already taking a beta-blocker, then this was phased out during the first 3 days of the control period. Subsequently, patients were treated for 6 weeks with one or other of the two trial drugs, the choice being determined by random selection.

Since diltiazem is given three times daily and atenolol once daily, the double-placebo technique was used, so that patients received either: (1) Diltiazem $60 \mathrm{mg}$ t.d.s. + placebo atenolol one each morning. (2) Placebo diltiazem 1 t.d.s. + atenolol $100 \mathrm{mg}$ each morning. The trial included patients aged 25 to $70 \mathrm{y}$, suffering from angina of either Class 2 or Class 3 severity (New York Heart Association classification). Class 2: stable effort angina occurring after the same degree of effort. Not interfering with everyday life. Class 3: intractable angina of effort occurring on minimal effort and interfering with everyday life.

Patients were only admitted to the trial if they were suffering from typical anginal pain with three or more attacks per week, and, where possible, showing definite electrocardiogram (ECG) changes after exercise. Patients were excluded if suffering from hepatic, thyroid, heart valve, peripheral vascular, renal or respiratory disease; mental retardation; unstable angina; anaemia $(\mathrm{Hb}<10 \mathrm{~g} / 100 \mathrm{ml})$; conduction abnormalities; dysrhythmia; diabetes mellitus; or infarction in the previous 3 months. Females of child bearing age were also excluded.

(C) The Fellowship of Postgraduate Medicine, 1985 
Patients continued to take trinitrate tablets for the relief of attacks only and antihypertensive drugs were continued provided that these were not beta-blockers. However, the following drugs were not given during the trial: beta-blockers, digitalis, amiodarone, or other calcium antagonists; if these were required on medical grounds, then such patients were excluded from the trial.

The patients themselves made daily records throughout the 8 week trial period of the number of attacks of chest pain, whether at rest or on exercise, and the number of trinitrate (TNT) tablets needed to relieve the attacks of pain. TNT was only used when necessary to relieve angina. The patients also recorded each evening how they felt during the day and how they were able to cope with exercise, respectively, on a four-point scale as follows: $0=$ worse, $1=$ the same, $2=$ better, and $3=$ much better. At the end of each 2 week period, the doctors measured pulse rate and blood pressure and made an overall estimate of global improvement (compared to control) as follows: $-1=$ worse, $0=$ no improvement, $1=$ improved, and $2=$ much improved. Side effects were only recorded if spontaneously volunteered by the patients and attributed to the trial tablets.

Differences between the control period and each period of the trial were tested for statistical significance using the paired $t$ test or Wilcoxon Signed Rank test, as appropriate. Between drug differences were tested for using the unpaired $t$ or Mann-Whitney test, as appropriate.

Records were received from 78 patients and on breaking the code it was found that 38 of these had received diltiazem and 40 atenolol, a very satisfactory distribution of cases between the two treatment groups according to the randomization method used. The two treatment groups matched one another very well in respect of these various items of patient data (Table I).

Table I Comparison of treatment groups

\begin{tabular}{lcc}
\hline & Diltiazem & Atenolol \\
\hline Number (M:F) & $38(24: 14)$ & $40(27: 11)^{*}$ \\
$\begin{array}{l}\text { Mean age ( } \pm \text { s.e.m.) } \\
\text { Range }\end{array}$ & $56.9(1.2)$ & $56.2(1.5)$ \\
$\begin{array}{l}\text { Mean weight } \\
\text { (kg } \pm \text { s.e.m.) }\end{array}$ & $32-69$ & $34-71$ \\
Range & $71.9(1.8)$ & $73.4(1.7)$ \\
$\begin{array}{l}\text { Mean height } \\
\text { (cm } \pm \text { s.e.m.) }\end{array}$ & $41-90$ & $51-104$ \\
Range & $168.3(1.4)$ & $168.7(1.7)$ \\
\hline
\end{tabular}

*Sex not recorded in 2 cases

\section{Results}

\section{Anginal attacks}

The results in relation to anginal attack rate and TNT requirements are shown in Table II. In both treatmen? groups there was a significant reduction in both anginal attack rate and TNT requirements at alf periods of the trial as compared to the control period? Thus, with diltiazem, the mean attack rate during the control 2 weeks was 24.4 and this had been reduced to 5 10.5 during the last 2 weeks of the trial $(P<0.001)$ The comparable figures for atenolol were: 21.5 (con $\vec{\omega}$ trol 2 weeks) reduced to 9.0 (last 2 weeks) $(P<0.001) \frac{\Omega}{\circ}$ Similar figures were recorded for TNT requirements $(P<0.001$ with both drugs). There were no significant between-drug differences at any period of the trial.

\section{Well-being and exercise tolerance}

The patients records of general well-being and exercise tolerance are shown in Table III. For both measures? there was statistically significant improvement at al periods of the trial with both drugs, as compared to the control 2 weeks. Thus, in respect of well-being, with $\vec{D}$ diltiazem the mean score during the control period was 14.2 , and this improved to 21.5 during the last 2 weeks of the trial $(P<0.001)$. The comparable figures atenolol were: 16.9 improving to $25.1(P<0.001)$. Theo mean score for exercise tolerance improved from 1 \% during the control period to 19.9 during the last 20 weeks of the trial with diltiazem $(P<0.001)$, and froms 14.4 to 21.1 with atenolol $(P<0.001)$. There were noo significant between-drug differences in respect of either measure.

There was significant improvement in the doctors global assessments with both drugs at all periods of the trial $(P<0.001$ last 2 weeks as compared to control $2=$ weeks for both drugs), but again with no significan? between-drug differences.

\section{Pulse rate and blood pressure}

There was a progressive reduction in mean pulse rate in both treatment groups, this being statistically significant from weeks 3-4 onwards with diltiazem? $(P<0.05)$ and from weeks $1-2$ onwards with atenolo $(P<0.001)$. Thus, with diltiazem the mean pulse rate was reduced from 80.9 initially to 76.3 by the end of the trial; the comparable figures for atenolol being: 77.9 initially, reducing to 70.9 by the end of the trial. There were no significant between-drug differences in respect $\omega$ of pulse rate. There was significant reduction in mean? systolic blood pressure with diltiazem from an initialo $146.3 \mathrm{mmHg}$ to $141.7 \mathrm{mmHg}(P<0.05)$; the com- $-\Phi$ parable figures for atenolol being $146.7 \mathrm{mmHg}$, re-ducing to $139.1 \mathrm{mmHg}$ by the end of the trialo 
Table II Mean figures ( \pm s.e.m.) for 2-weekly anginal attack rate and TNT requirements

\begin{tabular}{llrrr}
\hline \multirow{2}{*}{ Period } & \multicolumn{2}{c}{ Anginal attacks } & \multicolumn{2}{c}{ TNT requirements } \\
& Diltiazem & Atenolol & Diltiazem & Atenolol \\
Control period & $24.4(3.3)$ & $21.5(2.2)$ & $23.8(4.1)$ & $19.3(2.9)$ \\
$0-2$ weeks & $16.6(2.7)$ & $16.4(2.6)$ & $13.7(2.6)$ & $14.2(2.5)$ \\
3-4 weeks & $14.0(2.6)$ & $12.1(2.6)$ & $11.5(2.3)$ & $11.4(2.7)$ \\
5-6 weeks & $10.1(2.3)$ & $9.0(1.9)$ & $8.7(1.9)$ & $7.9(2.0)$ \\
& $13.4(2.4)$ & $11.4(1.8)$ & $11.3(2.1)$ & $10.4(1.9)$ \\
\hline
\end{tabular}

$(P<0.01)$. However, there was no significant reduction in diastolic blood pressure with diltiazem $(84.0 \mathrm{mmHg}$, to $83.3 \mathrm{mmHg})$ although there was a significant reduction with atenolol $(86.0 \mathrm{mmHg}$, to $81.2 \mathrm{mmHg})(P<0.01)$. There were no significant between drug differences in respect of either systolic or diastolic blood pressure.

\section{Side effects}

During the control period the proportion of patients experiencing no side effects at all amounted to $90 \%$ in the diltiazem group as compared to $74 \%$ during the trial period. The comparable figures for atenolol were: control $83 \%$, trial period $73 \%$. There was no significant between-drug difference in respect of the incidence of side effects and no particular side effect predominated with either drug (Chi-square).

With diltiazem there were no cases where treatment had to be omitted because of side effects, whereas in the atenolol group three patients had to omit treatment because of headache, bronchospasm and nausea respectively, and one suffered a myocardial infarction.

\section{Discussion}

The clinical evaluation of new drugs runs a fairly predictable course, starting with open studies for the purpose of confirming efficacy and establishing optimum dosage, and then double-blind comparisons firstly to placebo and then to standard equivalent drugs to establish comparative effectiveness. In the case of diltiazem, many of these studies have been undertaken in the USA and are concerned with its two main actions in hypertension and angina, respectively. Studies in hypertension have shown the drug to be effective with a duration of action of 8-12 h (Olivari et al., 1979); and in angina to have a maximal effect 3-8 h after dosage (Chaitman et al., 1984). Open and controlled studies have both confirmed the effectiveness of diltiazem (Hossack et al., 1982a,b; Strauss et al., 1982; Feldman et al., 1982).

Further comparative trials have been made with established adrenergic beta-blocking drugs and other calcium antagonists, although the latter are at present few in number. The beta-blockers are a heterogeneous group of drugs (Wheatley, 1981) and have a number of differing properties that may affect their effectiveness in angina. Two such important properties are cardiospecificity and lipophilia; the first involving actions other than those destined for the target organ that may be disadvantageous, and the latter determining the degree of peripheral or central activity. The choice is indeed catholic; ranging from the original non-cardiospecific highly lipophilic propranolol, through cardiospecific non-lipophilic drugs such as metoprolol and atenolol, to the cardiospecific lipophilic compounds such as betaxolol (Manoury, 1983). As the established 'standard', propranolol has been used for comparative purposes in many of the studies on diltiazem.

Such studies have confirmed the equivalent effectiveness of diltiazem (Chaitman et al., 1984; Yamak-

Table III Mean figures ( \pm s.e.m.) for 2-weekly scores in respect of well-being and exercise tolerance

\begin{tabular}{lcccc}
\hline Period & \multicolumn{2}{c}{ Well-being } & \multicolumn{2}{c}{ Exercise tolerance } \\
& Diltiazem & Atenolol & Diltiazem & $14.4(1.2)$ \\
Control period & $14.2(0.8)$ & $16.9(1.3)$ & $13.6(0.8)$ & $18.3(1.5)$ \\
0-2 weeks & $17.8(1.4)$ & $21.7(1.8)$ & $16.0(1.1)$ & $17.5(1.3)$ \\
3-4 weeks & $19.1(1.6)$ & $24.6(1.7)$ & $19.9(1.7)$ & $20.9(1.5)$ \\
$5-6$ weeks & $21.5(1.8)$ & $25.1(1.7)$ & $17.3(1.2)$ & $20.3(1.3)$ \\
0-6 weeks & $19.4(1.5)$ & $24.0(1.4)$ & $1.6)$ \\
\hline
\end{tabular}


ado et al., 1983; Tilmant et al., 1983) and this has been shown also against the cardiospecific drug metoprolol in hypertension (Trimarco et al., 1984). Verapamil and nifedipine are the two calcium antagonists most firmly established in clinical practice. Verapamil has been thought to be only moderately effective as an antianginal agent (Henry, 1980). Chaitman et al. (1984) compared diltiazem to nifedipine (as well as to propranolol and placebo), finding similar improvement in exercise tolerance of patients with chronic stable angina. However, the maximum effect of nifedipine was at $1-3 \mathrm{~h}$ after ingestion, as compared to $3-8 \mathrm{~h}$ for diltiazem.

This paper forms one of the later links in the research chain, comparing diltiazem to another established drug in the treatment of angina, namely atenolol. Despite the fact that there can be a strong placebo effect in anginal trials (Strauss et al., 1982; Wheatley 1979,1984 ), both drugs in this trial were shown to produce a highly significant reduction in the anginal attack rates and trinitrate requirements in comparison

\section{References}

AWAN, N.A., DeMARIA, A.N. \& MASON, D.T. (1982). Calcium antagonists in coronary artery disease and congestive heart failure. Medical Progress, 23, 95.

CHAITMAN, B.R., WAGMART, P., PASTERNAC, A., BREVERS, G., SCHOLL, J.-M., LAM, J., METHE, M., FERGUSON, R.J. \& BOURASSA, M.G. (1984). Improved exercise tolerance after propranolol, diltiazem or nifedipine in angina pectoris: comparisons at 1,3 and $8 \mathrm{~h}$ and correlation with plasma drug concentration. American Journal of Cardiology, 53, 1.

ELLRODT, G., CHEW, C.Y.C. \& SINGH, B.N. (1980). Therapeutic implications of slow-channel blockade in cardiocirculatory disorders. Circulation, 62, 669.

FELDMAN, R.L., PEPINE, C.J., WHITTEL, J. \& CONTI, C.R. (1982). Short- and long-term responses to diltiazem in patients with variant angina. American Journal of Cardiology, 49, 554.

HENRY, P.D. (1980). Comparative pharmacology of calcium antagonists: nifedipine, verapamil and diltiazem. American Journal of Cardiology, 46, 1047.

HOSSACK, K.F., POOL, P.E., CRAWFORD, M.H., DEMARIA, A.N., COHEN, L.S. \& PORTS, T.A. (1982a). Efficacy of diltiazem in angina on effort: a multicenter trial. American Journal of Cardiology, 49, 567.

HOSSACK, K.F., BRUCE, R.A., RITTERMANN, J.B., KUSUMI, F. \& TRIMBLE, S. (1982b). Divergent effects of diltiazem in patients with exertional angina. American Journal of Cardiology, 49, 538.

MCAULEY, B.J. \& SCHROEDER, J.S. (1982). The use of diltiazem hydrochloride in cardiovascular disorders. Pharmacotherapy, 2, 121.

MANOURY, P. (1983). Betaxolol: chemistry and biological profile in relation to its physico-chemical properties. LERS Vol. 1, Morselli, P.L. Kilborn, J.R., Cavero, I., Harrison, D.C. \& Langer, S.Z. (eds). p. 13-19. Raven Press: New York. to the control 2 week period. Therefore, diltiazem 3 represents a useful addition to the therapeutic $\stackrel{\mathcal{Q}}{\varrho}$ armamentaria available for the treatment of coronary $ᄃ$ heart disease. It may well have further advantages in $\overrightarrow{\vec{F}}$ respect of the specificity of action, tolerance and a low? incidence of side effects, that will emerge when the drug has been in widespread clinical use.

\section{Acknowledgements}

The following members of the General Practitioner Research Group took part in this trial: R.B. Deering, Burgess Hill: M.J. Derbyshire, Manchester; J. Gay, Chigwell; B.V. Harris, Bolton; R. Lal, London; F. Lustman, Newcastle-upon-Tyne; R.N. Midha, Swansea; R.P. Saxena, Port Talbot; A.G.E.os Smith, Telford; S. Sorkin, Leeds; J.M.T. Warnock, Tarbol-ton; T.M. Warren, Penygraig; G.J. Wilcox, Kidderminster; G. Zakaria, London. We would like to thank Dr K.D. MacRae of Charing Cross Hospital, London, for his assis-o tance with the statistical analysis.

NAYLOR, W.G. (1980). Calcium antagonists. European Heart Journal, 1, 225.

OLIVARI, M.T., BARTORELLI, C., POLESE, A., FIORENTI\&I, C. \& GUAZZI, M. (1979). Treatment of hypertension wience nifedipine, a calcium-antagonist agent. Circulation, 1056.

STONE, P.H., ANTMAN, E.M., MULLER, J.E. \& BRAƯN-O WALD, E. (1980). Calcium channel blocking agents in the treatment of cardiovascular disorders. Part II: Hemodyn-ō amic effects and clinical applications. Annals of Interna Medicine, 93, 886.

STRAUSS, W.E., MCINTYRE, K.M., PARISH, A.F. \& SHAPIRO, W. (1982). Safety and efficacy of diltiazem hydrochloride $\frac{O}{3}$ for treatment of stable angina pectoris. Report of $a^{\supset}$ cooperative clinical trial. American Journal of Cardiology, 49, 560.

TARTAGLIONE, T., PEPINE, C.J. \& PIEPER, J.A. (1982).흐 Diltiazem: A review of its clinical efficacy and use. Drug Intelligence and Clinical Pharmacy, 16, 371.

TILMANT, P.Y., LABLANCHE, J.M., THIEULEUX, F.A., DUPINI, B.A. \& BERTRAND, M.E. (1983). Detrimental $\varrho$ effect of propranolol in patients with coronary artery spasm countered by combination with diltiazem. Americano Journal of Cardiology, 152, 230.

TRIMARCO, B., DELUCA, N., RICCIARDELLI, B., VOLPE, M., VENIERO, A., CUOCOLO, A. \& CICALA, M. (1984). Diltiazem in the treatment of mild or moderate essential hypertension. Comparison with metoprolol in a cross-over double-blind trial. Journal of Clinical Pharmacology, 24, 요 218.

WHEATLEY, D. (1979). Clorazepate in the management of $\sigma$ coronary disease. Psychosomatics, 20, 195.

WHEATLEY, D. (1981). Beta-blocking drugs in anxiety. In Stress and the Heart, Wheatley, D. (ed), 2nd ed. p. 73-89. Raven Press: New York.

WHEATLEY, D. (1984). Anxiolytic drug use in cardiovascular $\frac{T}{0}$ 
disease: an overview. Psychopharmacology Bulletin, 20, 649.

YAMAKADO, T., OOMISHI, N., KONDO, S., NOZIRI, A., NAKANO, T. \& TAKAZAWA, H. (1983). Effects of diltiazem on cardiovascular responses during exercise in systemic hypertension compared with propranolol. American Journal of Cardiology, 52, 1023.

ZELIS, R. \& FLAIM, S.F. (1982). Calcium blocking drugs for angina pectoris. Annual Review of Medicine, 33, 465. 